\title{
Measuring the Cost of Noise Pollution and Its Impact in Reducing Corporate Profits, Income Tax Collections, the Treasury, the National Economy and the Welfare of Society
}

\author{
Ali Mustafa Magablih ${ }^{1}$ \\ ${ }^{1}$ Irbid National University, Jordan \\ Correspondence: Ali Mustafa Magablih, Irbid National University, Jordan. E-mail: Alimagablih@yahoo.com
}

Received: February 12, 2019

Accepted: March 18, 2019

Online Published: April 15, 2019

doi:10.5539/ijef.v11n5p59

URL: https://doi.org/10.5539/ijef.v11n5p59

\begin{abstract}
The aim of this study to define the concept of noise pollution and the cost of pollution from noise, it also aims to explain the cost of noise pollution on the profits of industrial enterprises, in addition to the recognition of the role of the Jordan Phosphate Mines Company to reducing the impact of noise pollution on workers, as well as the role played by the reduction of the costs of pollution and its impact on the profits of noise pollution to reducing treasury revenues.

And therefore could not measure the impact of the company incurring the costs caused by noise pollution on company profits in the absence of a clear classification of the causes of the cost and thus the difficulty of measuring the impact on the profits of the company, the results of the study also indicated that there are costs of noise pollution and a clear impact on the profits of the company.

This study focuses on the economic and social aspects which are of crucial importance in noise pollution that strongly affect the performance of the workers, the profits of industrial enterprises, and concludes that the noise pollution impact on staff performance and production as well as tax collections, the treasury and the national economy.
\end{abstract}

Keywords: noise pollution, reducing profit, income tax, treasury, national economy, welfare, society

\section{Introduction}

One of the most important issues that deserve study is "noise pollution" which affect individuals and society. Because of the rapid modernization of high technology and its impact on life, where many of the risks to the economy and the well-being of the communities as a result of the loss resulting from this type of pollution and their consequences for the workers, especially in industries that produce noise exceeding the allowed limit which brings about sick leave and reduced productivity and also brings about deafness (partial or total), all these facts thus adversely affect the national economy as a whole.

If, on the other hand, the medical, physical and environmental sciences has provided tools to measure the effects of noise on human beings and their environments, accounting did not give sufficient attention to this subject, like other economic sciences, as if it was separate from the environment in which they operate, or that this phenomenon outside its borders, although most noise pollutions are caused by the exercise of economic projects and activities.

It is therefore imperative that accounting is concerned, like other sciences to identify and measure the costs of noise and its impact on the economies of the unit, on the one hand, the costs of reducing the effects of noise and its reflections on the profits of enterprises.

\subsection{The Problem of the Study}

The industrial sector enjoys a distinct priority in designs on development by limiting their social and through the expansion of industrial companies with a view to providing goods and services to members of the community and provide employment and contribute to the support of the national economy.etc, accompanied by the activity of these companies often many negative environmental impacts that lead to obey those laws. Harmful environmental effects on human health and vegetation and the quality of the environment and natural resources and the ability to regenerate and continue. 
Through the listing of previous studies in the local environment studies, this study focused on social responsibility and environmental responsibility in terms of the definition and importance of disclosure, in the industrial companies not the study non-significant aspect of the environmental costs of the costs of noise pollution, one of the most dangerous types of environmental pollution on human rights, the environment surrounding the because its impact does not appear immediately, but after a period of time, hence this study complements the previous studies as to whether the Phosphate Mines Company defines and measures the costs of noise pollution and its impact on the company's profits.

\subsection{The Importance of the Study}

As a result of the massive developments at all levels in the world, and especially in the economic sector, that has started to float in recent decades and symptoms are frightening features an impressive environment and society and, as a result of economically developed countries started to increase balancing the social and economic cost of the environment and projects, as it affects society.and any sense of focus to define the concept of the social cost, including to ensure balance with the economic cost of the project.

Including the noise pollution and the type of environmental pollution from multiple sources, which notified the society has increased, especially on the labor force, where the cause of hearing deafness gradually lead to the disruption of oneself and the lack of scalability is the ability to work and produce, the judiciary system as a result of the additional economic burdens.

Noise is a type of environment pollution which issued in the form of waves which, if continued for eight hours and sevirity $85 \mathrm{Dbi}$, affect the human, and if more than leading to deafness, given the negative effects of noise pollution caused by industrial companies in terms of its impact on the workers, and therefore the low productivity in addition to the costs incurred by industries companies to reduce noise pollution, which cause obvious impact on the profits of this companies, and the impact of the noise pollution in the environment surrounding human beings living organisms, in view of the growing interest by many different parties in society, environment protection, which is considered as one of the aspects of social responsibility as the need for the imperative to the survival of companies in light of the growing interest in the social responsibility of the frequent claims by working to create a climate free from noise.

Therefore, lies the importance of this study in an attempt to know the causes of noise and identify and measure the costs of noise pollution and the impact of these costs on profits, and find solutions to reducing them in order to preserve the human component, which is considered one of the most important elements of the Sherpa production could not be process.

\subsection{The Objectives of the Study}

This study is designed to achieve the following:

1) Defining the concept of noise pollution and the cost of pollution from noise.

2) A statement of the costs of noise pollution on the profits of industrial enterprises.

3) Identify the role of the company to reduce the impact of noise pollution on workers, as well as the role played by the reduction of the costs of noise pollution and its impact on profits.

4) The statement of the impact of noise pollution on the performance of the staff in the industrial companies

5) Clarifying the role of the noise pollution on the profits of industrial enterprises.

6) The statement of the impact of noise pollution on tax collections and treasury

7) Clarifying the role of the noise pollution on the national economy

8) The search for the best ways and means to reduce noise pollution.

9) A statement of the impact of the costs of removing the noise pollution of the productive capacity of workers and the project.

\subsection{The Hypothesis of the Study}

1) Noise pollution does not affect the performance of workers in industrial companies.

2) Noise pollution does not affect the profitability of industrial companies.

3) Noise pollution does not affect the income tax and treasury

4) Noise pollution does not affect the national economy. 


\section{Previous Studies}

- Bombers and snipers, study (2015) entitled: (environmental cost accounting measurement and disclosure in the financial lists to improve performance), where this study addressed the issue of environmental cost accounting measurement and disclosure in the financial statements and to improve environmental performance, the application on a group of industrial companies in Algeria, one of the most important findings of the study is an awareness of the officials in these companies need to cluster the disclosure of costs and improve the environmental performance of industrial enterprises, as well as barriers to limit the application of the instrument panel and the disclosure of environmental costs.

- Study (Taher, 2011) entitled: (the extent of the commitment of the Civil Company for Cement to disclose environmental performance) This study aimed to identify the extent of the commitment of the Civil Company for Cement to disclose environmental performance, and to highlight the most important obstacles to the establishment of the factory in question to disclose environmental performance. The study came to the set of results, the most important of which is that there are many obstacles that limit the civil Company for Cement to disclose accounting for the environmental performance of the most prominent: the most prominent: the lack of educational programs to publicize the requirements for disclosure of environmental performance; the lack of an accounting system that fulfils the purposes of disclosure of environmental performance; the absence of binding laws of disclosure of environmental performance; the lack of desire of the disclosure of the costs associated with environmental damage resulting from its operations even if measured.

- Toranji, study (2008) entitled (the financial costs of noise pollution and social and economic units): This study aimed to determine by limiting their cost of the workforce in the project because of its exposure to high noise, and aimed to obey those laws. The costs of removing the noise pollution of the productive capacity of workers and the project macroeconomic policies, and on the application of the cement plant, a set of results, the most important: that the machinery and generators in the departments, Abbess makes noise more than the rates allowed, the study found that $31 \%$ of the total number of workers in the plant were infected in one way or another with the symptoms of diseases caused by noise, such as partial loss of hearing.

- Alhayali, study (2004) entitled: (measuring costs of noise pollution and its impact on the profits of industrial installations) one of the most important findings of this study that there is defining and measuring the costs of noise pollution and thus would not have been possible measuring the effect on profits.

- The study (Institute for Occupational Safety and Health Jordan in 1997), this study aimed to measure the levels of voice pressure for all components pollution by machines in 10 different industrial sites, they represent the broader, and Jordanian industries, exceeded the levels of noise of voice pressure machines in most of the selected sites. Many on the border noise, endorsed by the Arab Labor Organization, as prescribed by Convention No. 13 and private matters of occupational safety and health, amounting to $85 \mathrm{Db}$

The study concluded that the results were very dangerous to the health of the workers, the most important: Issued by most of the machines in the study of noise levels, the highest of the allowable boundaries, overcome high noise in many of the sites covered by the time allowed $(85 \mathrm{Db})$ according to the Arab Convention, $46 \%$ of the total incidence of partial loss of hearing.

- As seen (Broil \& Kjar, 1982) that the role of noise diseases resulting from the tension, such as; Blood pressure ulcers, and found that the high levels of noise may lead to numerous, such as diabetes or blood pressure or hardening of the arteries.

- The study of the world of the scourge of the age tone (noise), which dealt with the impact of noise on Human Rights concluded the following:

1) The specific noise measuring without $30 \mathrm{Db}$ did not result in any impacts of disturbing satisfaction.

2) The noise intensity within 30- $50 \mathrm{Db}$ affects the nervous sentence.

3) The noise intensity within 50-80 Db can cause obstruction to hearing the speech, the lack of hearing.

4) The noise which falls within the limits of $80-120 \mathrm{db}$ cause permanent disabilities in hearing devices, hormonal disorders, the high proportion of the blood, and the increase of the heart, coronary artery disease, lower body immunity infectious diseases, ulcers and high blood pressure.

5) The noise increase measuring $120 \mathrm{db}$ in addition to the diseases to sabotage the hearing devices, and in some cases lead to death. 


\section{- The study of the National Research Center in Cairo, Egypt}

The Center conducted a study on the impact of noise on the power of hearing for personnel and reached the following conclusions:

1) The personnel in the Cairo International Airport runway have early signs and hearing loss by $(62 \%)$ and traffic by $(8.1 \%)$, the car drivers $(8 \%)$.

2) The existence of a direct relationship between the degree of deafness and to noise.

3) That (62\%) of Cairo inhabitants take sedative drugs.

4) Blood pressure rises higher for those exposed to noise (33\%), and leads to a reduction in the production rate $(14 \%)$.

The study proved that the most important causes of noise pollution (audiovisual) in Cairo is the traffic problem caused by the horns that (150 DB), this measure may be injured by an imbalance in the balance of human rights, and damage to the hearing and nervous system.

The study of Dr. Abdel Ilah Blessings Jaafar, which dealt with the impact of accounting for the social costs of environmental pollution and the economics of the industrial project, to deal with the costs borne by the economic unit as a result of their activities leading to the pollution of the environment and its negative impacts on society in terms of psychological and mental health of the national macro-economy in general. A study by Dr. Walid Alhyali measuring costs of noise pollution and its impact on the profits of the economic projects), the study aims to propose a method of measuring the cost of noise pollution, and the impact of pollution abatement costs on the economy economic units, and the national economy.The difference between research and study, Dr. Walid used the questionnaire form from the field researcher that visited serginar cement plant in addition to the conclusion of the total annual economic cost of workers exposed to noise 0 study shows the impact of noise pollution on efficiency, focus on work, production, and increases the proportion of fatigue and exhaustion . In America, as a result of the exposure of workers higher noise any more than the allowed limit in America, (90 DB) for eight hours, concluded some accidents, absenteeism from work and lack of focus. The lack of efficiency and lower production, including material losses, were estimated to be equivalent to about (4000) million in 1971.

- Another study concluded that the social cost of transport noise in the 22 European countries was more than 40 billion euros annually.

- The 16 million workers in the United States complain of noise damage in the factories where they work.

One of the most difficult things in human life not only take enough time of sleep and rest because of noise, it is one of the most causes of psychological stress, mental and nervous disorders, and is one of the biggest obstacles to the efficiency of production and employment. The United Nations has given a week to fight the noise in the world and coming out with the slogan was "calm the taste and morals of ignorance and underdevelopment, noise".

The workers who are exposed to noise in excess of the limit (85 decibels) causes them according to the following previous studies.

- Audio disorders;

- The psychological and physiological effects;

- Sick and the deviation of the incidents in the sick leave;

- The weakness of lowering of production and lowering of the economy of the State.

\section{Study Methodology}

The descriptive and analytical approach was used to determine the characteristics of the phenomenon of noise pollution and explained the nature and quality of the relationship between the performance of workers in the industrial companies on one hand and the causes and trends as well as the annual report of the Phosphate Mines Company in 2016 to guide him.

The researcher also adopted various methods to collect information, studies and data on the ways and means through the following:

1) The use of modern means of communication (Internet) in the collection of information and data and studies to enrich the subject of research.

2) Desktop search by reference to various Arab and foreign sources, which dealt with the environment and environmental pollution in particular types of noise pollution. 
3) The researcher used the descriptive analytical approach method to determine the concept of noise pollution and its problems.

4) Depending on the results of some medical studies and physical (Decibel - db ) identified the degree of hearing loss .

5) The researcher adopted the accounting, financial data and information to determine the costs of noise pollution through the annual report of the company

6) Referred to the previous studies that paid attention to the social costs of environmental pollution and noise pollution, and their impact on national macroeconomic and industrial companies.

\subsection{The Study Society}

The study includes industrial companies in Jordan Phosphate Mines Company and contributes to the General Assembly and its affiliated companies as a model to study the impact of noise pollution on staff performance and profitability, and the treasury and the national economy, where there are 866 industrial companies in Jordan, 63 General contribution is limited.

\section{Results}

\subsection{The Measurement of Noise Levels in Accordance with the OSHA Specifications}

The maximum allowable daily to hear noise or noise pollution

$\begin{array}{ll}8 \text { hours ago } & 85 \mathrm{Db} \\ 4 \text { hours ago } & 88 \mathrm{Db} \\ 2 \text { hour } & 91 \mathrm{Db} \\ \text { Hours } & 94 \mathrm{Db} \\ 30 \text { minutes } & 97 \mathrm{Db}\end{array}$

15 minutes 100 DECIBELS

In Jordan, there are several laws related to pollution

- Jordanian Traffic Law No. (49) of 2007;

- The Environmental Protection Law No. (52) of 2006;

- Help reduce noise Prevention Act of 2003;

- The Social Security Act No. 1 of 2014;

- Evidence of accidents and injuries through Jordanian social security institution.

Social security obligations in Jordan:

- The costs of medical treatment and accommodation in hospital;

- The wounded transfer cost;

- The services and facilities, including the industrial parties;

- Salaries and compensation to the injured;

- The salary of death arising from work injuries and according to law, the equivalent of the salary of the working group on the top of his work and may be the cause of death as a result of the noise pollution;

- The salary of the poor total permanent disability and deafness injuries as a result of noise pollution in this area;

- The salary of the poor, partial disability may be the result of noise pollution and estuaries partial deaf and deserves the salary of the poor.

Compensation for the parent and the installment

- According to the social security statistics, the number of days of absenteeism 2014 (141002) on, as the cost of the injuries the same year 1794035 Jordanian dinars (US $\$ 1=(0.706)$ Jordanian dinars.

The social security deficit grew by $40 \%$ as a result of their exposure to deaf partially (Tongans often have strong ties $\mathrm{db}$ ), as well as by the inability of $60 \%$ for those who are more than $85 \mathrm{Db}$.

Most studies indicate that in the world that all forms of industries are affected by noise pollution at least 80 decibels loft, all professional staff including engineers, as a result of field conditions of their work in the 
mines and the factories of the company are subject to the proportion exceeding the allowable pollution mark $(85 \mathrm{Db})$.

High noise is considered one of the most important reasons for accidents, according to the Jordanian social security bulletins (noise pollution).

\subsection{Measuring the Cost of Noise Pollution}

Of the number of workers in the Phosphate Mines Company in 2016 according to the report of the company there were 3,293, and of them, 2509 were engineers and technicians with the remainder serving in administrative positions of the Phosphate Mines Company with it having three subsidiary companies that is as follows:

- Jordanian Japanese fertilizer company with a total staff of 125, including 98 engineers and technicians and the rest being members of the administrative cadre.

- The vision of land carriage company owned by the phosphate mines and the number of professionals that had 10 workers

- The Indian company for chemicals and owned by the Jordan Phosphate Mines Company and the number of personnel, 372 of whom were 295 engineers and technicians

The Phosphate Mines Company operates several locations and mines and these are namely, Rusaifa, Hasa, White House, Al Aqaba, the industrial complex, the new port project) and this amounted to the salaries paid to the company in 2016 (63115626 dinars salaries; 2802673 dinars of processing; 2250000 dinars contribution to the post-retirement insurance fund; 17069531 dinars salaries and wages paid to employees of the companies).

According to the findings of previous studies, the results will be guided to achieve the desired results, the search according to the following, note that the company has very high instructors insurance after retirement, they are certain that the workers after retirement need huge sums to affect them and their families and well-being if at their own expense if left without him as a result of what they endured during their work in the company which shows that workers are exposed to high rates of pollution, noise, and more physical abilities.

\subsubsection{The Cost of Sick Leave}

Scientific research confirmed that sick holidays for employee who are exposed to high level of noise (more than $85 \mathrm{Db}$ ) is 6.2 days worker annually, while the sick leave to workers who are subjected to noise (less than 85 decibels) 4 days worker annually, could entail a cost that computes sick leave for workers in the company as follows:

1) The degree of the deviation of sick leave for workers who are exposed to the severity of the voice of the increase of the $85 \mathrm{db}=6.2$ on annually -4 day annually $=2.2$ on annually.

2) The daily wage $=$ average salary for the month $/ 30$ days

3) The annual cost of sick leave per worker = average daily wages for the worker $\mathrm{x}$ annual difference for holidays

The total annual cost of noise pollution resulting from sick holiday for workers in a noisy environment most allowable (85) $\mathrm{Db}=$ The annual cost of sick leave per worker $\mathrm{x}$ number of workers employed in the atmosphere of high noise.

The average worker's wage per day

$63115626 / 3293 / 12 / 30=53$ dinars average daily wage

$=2.2 * 2509 * 53=292550$ dinars cost of sick leave in excess of the normal limit Phosphate Mines Company Alone;

$17069531 / 538 / 12 / 30=88$ dinars, the average daily wage for workers in subsidiary companies;

$2.2 * 403 * 88=78020$ dinars cost of sick leave in excess of the limit in subsidiaries;

$292550+78020=370570$ dinars cost of sick leave in excess of the limit of the company as a whole.

4.2.2 The Cost of the Low Efficiency and Productivity of Employees as a Result of the Noise Pollution

According to scientific studies and research that have been referred to a similar company with this study, the rate of decline in the productivity of the working group, which is exposed to noise $30 \%$ :

The cost of the low efficiency and productivity of the working group= annual salary of the worker annual $\times 30 \%$

Lower the total cost of the efficiency and productivity of factory workers annually. 
$=$ the cost of low efficiency and productivity per $\mathrm{x}$ number of the annual working factory who were exposed to noise that allowed

$19167 * 30 \% * 2509=14426702$ Jordanian dinars low productivity of the company

$31680 * 30 \% * 403=3835885$ Jordanian dinars low productivity of affiliates subsidiaries

$14426702+3835885=18262587$ Jordanian dinars low productivity of the company as a whole

\subsubsection{The Company's Loss as a Result of the Noise Pollution}

$=$ loss resulting from the deviation of sick leave +loss resulting from reduced productivity +contribution to the Health Insurance Fund after retirement

$18262587+370570+2250000=20883157$ JD's Loss

\section{1) The impact of the cost of the noise pollution on the profits of the company}

The result of the company for 2016 in the amount of (84883000JD) loss, the loss of the company reduced this amount to become( 63999843jd). This is apart from the cost of employing psychological and social costs of company employees and their families and the community members as well as except for the costs incurred by employees at their own expense as a result of their doctors and specialists are not available in the company.

From the above, it is clear the amount of high cost and noise pollution on company profits and this cost if we tried to present the results to all industrial companies, resulting in this kind of pollution, as well as to psychological and social effects of the personnel in these companies.

\section{2) The impact of Occupational Deafness micro- and macroeconomic policies on the national economy}

The results of a study conducted on similar plants of this company that part of those who are exposed to noise in excess of the limit are partially deaf or total and deserve compensation for work injuries and the workers who are between 85-95 db suffer partial deafness and between 96-120 decibels suffer deaf holistic and deserve compensation and who are exposed to more than 120 decibels may bring about their death.

According to the Social Security Act is, the Jordanian calculation is as follows:

The salary of the dead is according to the following equation=Pay Monthly-controlled $* 75 \%+40$

Calculate the salary of the total deficit $=($ salary paid monthly controlled $* 75 \%+40)+25 \%$.

Calculate the salary of partial disability $=$ (monthly salary under* $75 \% *$ deficit rate determined by the Commission $)+40$

The calculation will be in accordance with the following schedule:

Table 1 . The amount of compensation is determined by the law of the implied social

\begin{tabular}{lccc}
\hline The situation & The number & Compensation (Salary & The annual compensation \\
\hline (The main company's death & 6 & 1237.75 & 89118 \\
The death of subsidiaries companies & 1 & 2023 & 24276 \\
Total deficit - the main company & 34 & 2787 & 1137096 \\
A total deficit subsidiaries companies & 12 & 2524 & 363456 \\
Partial failure main company & 46 & 578.9875 & 319601.1 \\
Partial failure subsidiaries companies & 18 & 932.35 & 201387.6 \\
The total & & & 2134934 \\
\hline
\end{tabular}

The national economy losses $=$ company losses + compensation for work injuries

$=20883157+2134934=23018091$ Jordanian dinars equivalence to ( $\$ 32603528$ US dollars) loss of the national economy as a result of the noise pollution in the company

This is a logical, where the company is one of the biggest industries in Jordan if we take into account, the industrial firms would be the loss of the national economy and this is only for noise pollution if we add the loss of foreign pollution of factories and loss of land and air transport, and all that is related to the noisy environment, which will override the billions lost to state taxation, the depletion of the treasury and thus the welfare of the community 


\section{Conclusions and Recommendations}

\subsection{The Conclusions of the Study}

From the preceding analysis, the study on the identification and measurement of costs of noise pollution and the profit of the Phosphate Mines Company, one can conclude as follows:

1) The results of the study showed that the company does not identify and measure the costs of noise pollution and therefore could not measure the impact of the company that incurred the costs caused by noise pollution on profits.

2) Through the study, it was found that the cost of the noise pollution is high in the company resulting in the reduction of the company's profit or loss in the case of Phosphate Mines Company in 2016

3) The results of the study showed that the impact of the cost of noise pollution on the profit company as the company is subject to income tax, reducing the treasury revenues from taxes

4) Noise pollution is one of the forms of environmental pollution, social responsibility, accountability, and business establishments to shoulder social responsibility in reducing noise pollution and ultimately leads to an increase in the rate of economic performance in the case study were loading the national economy as a result of the noise pollution burdens could have been avoided if the companies abide by laws and regulations and the effective implementation of the principle of self-censorship of social responsibility.

5) Through the study and analysis it was indicated that the costs of noise pollution in the industrial companies have a negative impact on the economy, it was possible for these costs to increase corporate profits, leading to increase income and reduce the budget deficit and investment cpj projects on the community welfare and the reduction of unemployment and poverty.

\subsection{Recommendations}

Building on previous results, these are the following recommendations:

1) Because of the clear impact noise pollution on profits recommended that industrial companies to identify and measure the costs of noise pollution classification of the cost accurately from which you can download the costs by causing them.

2) Follow the best ways and means to reduce the noise level, modern approaches to the rate allowed (85Db) including:

- $\quad$ The use of modern equipment and machines to reduce noise in the companies.

- Install the STANDOFFS to the walls and ceilings of the absorption of the sound.

- $\quad$ Reforestation of the company, especially the updated sites noise, because trees absorb the sound.

- Even if a fraction of the teaching material as to pollution in general and its impact on the outcome of the economy and the welfare of society via educating future generations

\section{References}

Anonymous. (1998). The possibility of the expression of the environmental and social performance by limiting their facilities through the intellectual framework of accounting theory. Journal of Contemporary Business Research.

Atiya, M. R. (2000). The role of environmental auditing in the rationalization of decisions. Research Journal of Commerce, (2).

Bebbington, Unerman, \& O'Dwyer. (2014). Sustainability Accounting and Accountability.

Darwish, M. S. (2000). The assessment of the role of the Informatics in the reduction of the pollution of the environment, green manufacturing in industrial organizations. The Scientific Journal of the Economy and Trade. Faculty of Commerce, Ain Shams University.

Dust, A. F. (1997). Under the proposal to review the environmental issues in the light of the growing trend to support sustainable development issues. The Scientific Journal of the Economy and Trade, (2).

Gray, Adams, \& Owen. (2014). Accountability, Social Responsibility and Sustainability: Accounting for Society and the Environment. Pearson Education.

Help reduce noise Prevention Act of 2003.

International Institute for Sustainable Development. (2017). Cost of pollution in Canada 2017. International 
Institute for Sustainable Development.

Jordanian Social Security Institution. (n. d.). Evidence of accidents and injuries.

Jordanian Traffic Law No. (49) of 2007.

Mohamed, H. (2000). The reality of the cost data in Libyan companies and methods developed for financial accounting and administrative reports. Academy of Postgraduate Studies, Tripoli.

Muhammad, A., \& Abd, B. Y. (n. d.). Pollution control and environmental protection. King Saud University, Kingdom of Saudi Arabia.

Nodded. (2006). Research methods in management the entrance to build research skills. the house of Mars, The Arabization of the Ismail Basyouny.

Omar, M. I. (2002). Introduction to environmental sciences. Dar Salaam scientific books for publishing and distribution.

Schaltegger \& Burritt. (2000). Contemporary Environmental Accounting: Issues, Concepts and Practice, Greenleaf.

Shehata, H. A. (2000). Noise pollution, and impeding development. Casablanca, Engineers.

Taehoon, H., Chang, Y. J., \& Joowan, P. (2015). Prediction of environmental costs of construction noise and vibration at the preconstruction phase. Journal of Management in Engineering, 31(5).

Taher, A. Al B. H. (2011). Accounting disclosure of environmental performance in the cement civil war in Libyaprospective study. Journal of Damascus University, Economic, Legal, Syria, 27(1).

The Environmental Protection Law No. (52) of 2006.

The Social Security Act No. 1 of 2014.

United States Department of Labor. (n. d.). Occupational Safety and Health Administration.

Walid, N. (2004). Studies in contemporary accounting problems, and the models proposed (1st ed.). Dar al-Hamed for publishing and distribution.

\section{Copyrights}

Copyright for this article is retained by the author(s), with first publication rights granted to the journal.

This is an open-access article distributed under the terms and conditions of the Creative Commons Attribution license (http://creativecommons.org/licenses/by/4.0/). 